\title{
The Reform of Teaching Method of Communication Principle
}

\author{
Hou-Qin WEI ${ }^{\mathrm{a}}$ and Yan-Ming $\mathrm{CHENG}^{\mathrm{b}^{*}}$
}

College of Electrical and Information Engineering, Beihua University, Jilin, China

a8121824@qq.com, b 8900977@qq.com

${ }^{*}$ Corresponding author: Yan-Ming CHENG

Keywords: Communication principle; Interest; Heuristic teaching; the simulation software

\begin{abstract}
Communication Principle" has characteristic which the content is various, theoretical is strong, comprehensive is high, causes the study of curriculum quite boring, in order to improve the teaching quality and effect of " communication Principle", combining with the characteristics of the school teachers and students resources and hardware equipment, the article emphatically from the current situation of teaching, the teaching method and practice etc, systematically puts forward the scheme of teaching reform, and the teaching effect has been improving obviously.
\end{abstract}

\section{Introduction}

The curriculum of "Communication Principle" is not only the one of professional basic course of the electron, the information, and the correspondence, but also is one of admission to graduate study subjects. it plays a important role between the professional course and the basic course, covers the basic theory, basic knowledge of the communication system and transmission principle, in order to make students master basic theory, basic skills and basic analysis methods, and to lay a solid foundation of the subsequent course of study, such as "the optical fiber communication”, "mobile communication" and "satellite communication" and other courses. It is possible to make the student be calm in face of rapid development nowadays and in the future work and the further study has good ability of theoretical basis and support. But because the curriculum which is on the base of "Complex variable function", "Signal and System" "High frequency Electron", involves the concept and the theory are abstract and contents which covers from the sender to the receiver all related content which including the source of information measurement, the features of channel and noise. The principle of different communication system, channel coding and decoding, signal modulation and demodulation, synchronization technology, etc. are extensive[1,2]. This content needs more mathematical deduction, strong theoretical, high comprehensive, it is difficult to understand and grasp for students, So in a short period of time how to understand and grasp it, is not only every student's duty, but also the responsibility of the teacher's. Therefore, the teaching reform is imminent.

\section{The current situation of teaching}

Traditional teaching methods are mainly cramming teaching in class, the content involves the formula derivation and obscure theory. It is difficult to student to learn. For example, the power spectral density of power signal, energy spectrum density of energy signal , the signal correlation function which is related to the signal and system, it is difficult to make students establish perceptual knowledge from the perspective of signal. Learning this course is boring . There is a lack of enthusiasm, initiative [4]. No novelty, no pressure, no reflection process, make the teaching effect is poorer.

At the same time, under the impact of the market economy, many students valued practical ability and short-term profit point of view, are not interested in this kind of theory course, think that these courses are little use for future employment. Students pay more attention to the "single chip microcomputer", "C programming language", "electronic technology" course , take these courses as the key of future employment, thus they cultivate themselves according to the cultivation of the 
vocational college students plan calls. They ignore the study of communication course , learning only for a test.

\section{The reform of teaching method}

\subsection{Arousing students' interest in learning}

Interest is the best teacher; the interest is mainly derived from the demand and curiosity. First of all, we have to let students feel the important role of the development of the communication which bring the significant influence of people's life.[4] For example, why is WiFi everywhere now? Why can we download and upload the video or game anytime and anywhere? Why can We Chat everywhere now? At the same time, the development trend of communications, demand and wages are taught to students which can encourage students, this makes their job prospects are full of confidence and hope!

At the same time, due to the mathematical deduction, we can remember some typical signals of Fourier transform, using time shift characteristic of the Fourier change, frequency shift characteristics and symmetry, soon find the some other function of Fourier transform. So we avoid the trouble to deduce every time. At the same time, it is necessary to carry out laboratory associated with teaching content, let the students better consolidate and understand the theoretical knowledge in teaching. For example, After learning ASK, FSK, PSK, DPSK, etc, carry out the relevant test in a time, and put forward the question. Let students to master the principle, make every class Happy and interesting.

\subsection{The traditional teaching method combined with modern teaching mode}

"Communication principle" is more boring, it is urgent that how to deal with this problem is every teacher' Responsibility. Traditional teaching cannot meet this need. So it is time that the traditional teaching unify the modern multimedia teaching which is visualization and dynamic[5,6].This will stimulate the students' learning motivation and interest, improve teaching efficiency, enrich the teaching contents and forms, simplify complex issues, inspire the students' learning potential.

Protel, EDA, and Matlab has been applied to teaching, for example, in the demonstration of the AM modulation system, we can use matlab/simulink to Modeling and Simulation. The principle diagram of the AM is shown in fig1[3].

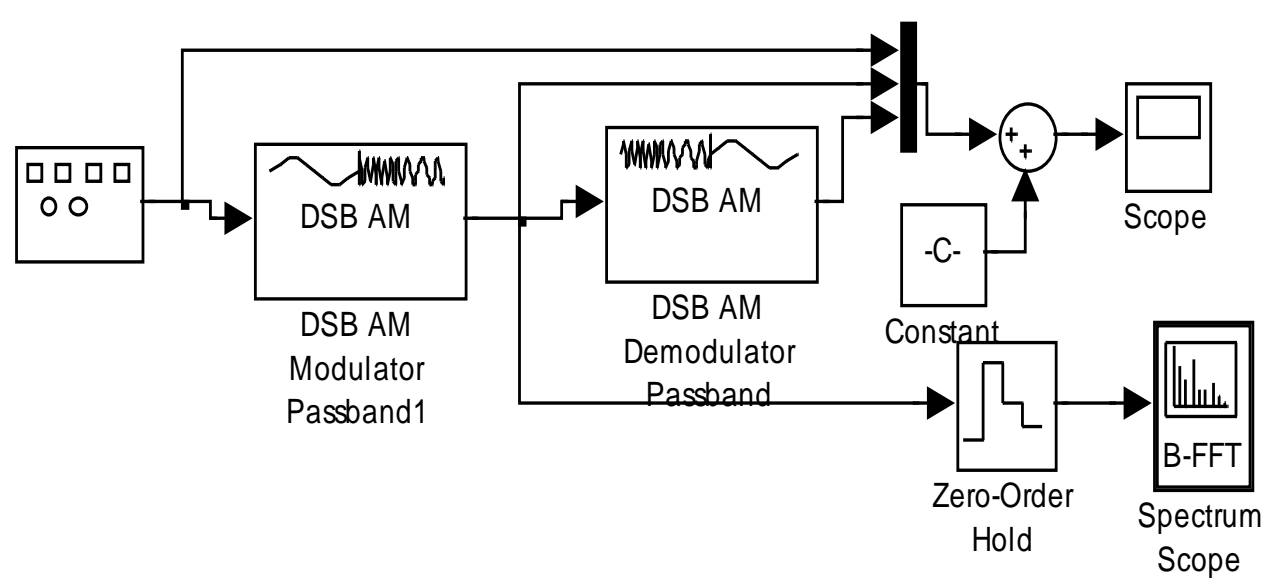

Fig.1. The principle diagram of AM

Guide the student to observe the waveform of each node in the time domain from scope and frequency spectrum in frequency domain from Spectrum Scope, make student understand and master the working principle of AM system and analysis method of system performance, if we change the parameters of DSB AM, observe the change of the waveform and frequency spectrum, and further understand of the relationship between the AM envelope and modulation coefficient. 
We can see that modulation index meet the need of AM,AM signal envelope modulated signal exactly the same as that of the original modulation signal, so the AM signal demodulation with envelope detector, and the detector which do not need carrier synchronization is simple .It is the reason that modulation efficiency is low but still be used. if modulation index does not meet the need, namely AM modulated signal envelope is not in conformity with the original modulation signal, therefore we can't use the envelope detection method for demodulation. At the same time, we observe the frequency spectrum that the existence of large carrier is the main reason for decline in modulation efficiency. The bandwidth of modulated signal is twice the modulation signal. Through matlab/simulink to AM system modeling and simulation, which simplifies the complex computing from time domain to frequency domain ,makes complex mathematical become very specific ,image, and makes it easier for students to accept the system working principle and the analysis method of system performance, learning interest is fully mobilize, learning effect is better . At the same time, the teacher guides the student to analyze the shortage of AM, requires the students to design a new modulation system, optimize system performance, the derivation of the DSB, SSB is a natural thing to do.

\subsection{Talking about Teaching}

According to the content of each chapter and teaching objectives teaching purpose, the question of the communication around the life is asked, which requires students to use the learned knowledge to think about the answers [7].Put a sure to the correct answer, and put a query to the wrong answer. With doubt step into the study of this chapter, when the chapter content or a content is completed, the learned content is asked, through the teachers and students are in the form of questions and answers, By this way, we can deepen and consolidate learned content.

For example, in the part of the response, the teachers can put forward the following problems, what is a part of the response? What is the advantage of Part of the response? What is the fourth part of the response? This can let the students to look for the answer in the form of group discussion. Then teachers spot check students, cultivate students' Self-study ability and teamwork ability.

\subsection{Elicitation method of teaching}

Communication principle course content is more, deduction is various, different communication systems have a lot of similar deduction [8]. For example, modulation mode and performance analysis, can be in a similar way modulation method of the digital communication system. In the process of teaching, it is necessary to cultivate the students to ask questions, to analyze questions and solve problems. Fully the enthusiasm of students is awakened; this makes students become the real master. Create a harmonious classroom atmosphere!

\subsection{Teachers' lifelong learning}

In addition, due to the communication of the new technology constantly emerging, the existing old technology constantly eliminated, many of our familiar technology continues to be replaced. For example, the SDH gradually fade out in our vision. Therefore, the teachers, should constantly learn new technology, understand the development trend of communication, constantly improve the teaching quality and keep up with the pace of times.

\section{Improving traditional methods, training students' practical ability}

Previous experiment to be selected was used for the theoretical experiment, fundamental experiment,on the same time, which should be add some comprehensive and innovative experiment, Traditional experiment was used for the theoretical experiment, students who don't even understand the principle can connect circuit only according to the steps, complete the experiment, so students are in a passive position, are lack of enthusiasm, the experiment result is not good. The author thinks that the education should cultivate comprehensive innovative talents, change from single mode to a variety of model. In the experimental teaching content based on the experiment of adding some comprehensive and innovative experiments. The proportion of comprehensive and innovative experiments in the experimental teaching should be on the rise. 
The students Can use EDA experiment platform, for example, can use some special integrated chip to structure communication system, the integrated chip can avoid to use more sorts of line and circuit. The integrated chip, simplify the circuit. it is an opportunity of EDA general hardware platform to achieve all of the experiments. Using EDA technology, the student must master experiment content to write your own program. This will greatly mobilize the students' creativity and initiative, has a great help to improve students' interest in experiment.

The students should master certain professional knowledge, and experimental operating skills, and can use one or more courses for comprehensive experiment design and operation. By this way, it can cultivate the students' innovation consciousness and practice ability, improve the comprehensive quality of students. At the same time, the experiment class arrangement and difficult to control should be considered. The source of case selection, can be in excellent scientific research achievements by simplifying ,modifying some project, and to reconstruct communication class experiment case; can be in Competition in electronic contest, the innovative and forward-looking, practical solutions can be modified as case; Can be also in electronic journal newspaper or scientific papers, scientific papers is usually the latest cutting-edge technology is introduced in this professional, discussed and summarized, it can be chosen.[9]

Experiment content should be comprehensive, interesting, practical and the characteristics of communication. Students can choose title according to their own interests and hobbies, 4-5 students form a team, choose their interested experimental project for comprehensive experimental skills training. Such as, wireless environment monitoring, remote control, wireless remote control, simplex wireless paging, etc. In the process of experiment, the students play a leading role; independently complete the experiment design and management experiment. Teachers only make macroeconomic regulation and control. The appraisal effect pays great attention to the practice process; pay more attention to students encounter difficulties in practice when dealing with the attitude of the problem and the team cooperation ability [10]. Through the experiment, the students not only master the communication professional comprehensive knowledge, but also learn to calmly cope with setback ability and the team cooperation ability.

\section{Conclusions}

"Communication principle" is a difficult and hard to teach course, it is only way to the improve in teaching contents, teaching methods, teaching means, to constantly collect students' feedback, gradually improve the teaching mean, so it can fully arouse the enthusiasm of the students. But the development of communication technology and network technology is very quick and constantly update, the application domain expands unceasingly, which requires that we constantly absorb new knowledge in the process of teaching, which can fully mobilize students' learning initiative and enthusiasm, cultivate students' learning ability by themselves, deepen the interaction between teachers and students link. This can create pleasant and harmonious classroom atmosphere.

\section{References}

[1] Cangxin Fan. Communication Principle[M].BeiJing,The defense industry publishing house,2015.

[2] Zhigang cao. Modern communication principle [M]. Beijing, tsinghua university press, 2008.

[3] Yuanming xu.Matlab simulation application in communication and electronic engineering[M].xian,Xian university of electronic publishing house,2010.

[4] liu Chao, etc. Communication principle of curriculum reform research and thinking [J].Electric power education in China, 2010(5):125-127.

[5] Rongfen Zhang . "modern communication principle of" innovation, such as the teaching exploration and study "course education research[J], 2013(7):254-255. 
[6] Qin Xue .Teaching Reform and Research of the Course of Communication Principle Based on SystemView.[EB/OL].[2010-04-29].http://en.cnki.com.cn/Article_en/CJFDTotal-JYJS2010040 16.htm.

[7] Ya-qiongzhang,Huan-Huanzheng.Reform and Exploration of Communication Principle Experi mental Teaching for the Cultivation of Applied Talents[EB/OL][2013-04-29].http://lib.cqvip.co m/qk/83804A/201604/669424829.html.

[8] Lihui Zhong. Teaching reform of the coures of the communication principle experiment based on the MATLAB[J].Electronic Technology \& Information Science,2012,6,135-216.

[9] Gangcan Sun.A Teaching Case of Communication Principle Course Using Matlab[J]Journal of Henan Institute of Engineering,2011(4):123-127.

[10]Yingxin Liu. College teaching reform[N]. Wen hui bao, 2014 (6):9. 